\title{
PENGARUH MOTIVASI KARYAWAN TERHADAP KINERJA KARYAWAN DI PT. XYZ
}

\author{
Inriana Tiara Agnesia \\ Program Studi Magister Manajemen Universitas Tarumanagara \\ Inrianatiaraa@yahoo.com
}

\begin{abstract}
The purpose of this research is to find out the variables that affect the employee performances in PT. XYZ. The population consist of employee of PT. XYZ using probability sampling method that of 127 respondents, 85 (67\%) were male and $42(33 \%)$ were women.. Data analysis using multiple regression analysis technique. The results of the testing of hypotheses shows that physical work environment, remuneration, status, social work environment, recognition, supervision, work itself, achievement has significant influence to employee performances.
\end{abstract}

Keywords: Motivation, Employee Performances

\section{Latar Belakang}

Dunia Perbankan yang saat ini semakin berkembang dan kompetitive merupakan suatu gambaran kondisi perekonomian di Indonesia yang semakin baik, sejalan dengan perkembangan tersebut setiap Bank terus berinovasi untuk memperluas jaringan dan nasabahnya, salah satunya mengelola usaha kartu kredit yang saat ini hampir seluruh Bank di Indonesia (Pemerintah, Swasta \& Asing) telah melakukannya sehingga timbul persaingan yang sangat ketat.

Dokumen penting yang dimiliki oleh perusahaan perbankan tentu saja tidak sedikit, apalagi jika perusahaan itu mempunyai nasabah yang banyak. Mengirimkan dokumen yang banyak dalam waktu cepat masih agak sulit untuk dilakukan. Biasanya jasa pengiriman lain menyanggupi mengirimkan banyak dokumen namun dalam beberapa hari. Memang pasti, dokumennya akan sampai, tapi jika waktu pengirimannya lama, pastinya akan tetap merugikan bagi perusahaan. Banyaknya arus pengiriman dan membutuhkan waktu yang cepat maka perusahaan harus memotivasi karyawannya agar kinerja karyawan dapat meningkat sehingga tidak terjadi keterlambatan pengiriman dokumen dan perusahaan tidak merugi.

Setiap organisasi dituntut untuk dapat mengoptimalkan sumber daya manusia dan bagaimana sumber daya manusia dikelola. Pengelolaan sumber daya manusia tidak lepas dari faktor karyawan yang diharapkan dapat berprestasi sebaik mungkin demi mencapai tujuan organisasi pemerintah. Karyawan merupakan asset utama organisasi dan mempunyai peran yang strategis didalam organisasi yaitu sebagai pemikir, perencana, dan pengendali aktivitas organisasi. Demi tercapainya tujuan organisasi, karyawan memerlukan motivasi untuk bekerja lebih rajin. Melihat pentingnya karyawan dalam organisasi, maka karyawan diperlukan perhatian lebih serius terhadap tugas yang dikerjakan sehingga tujuan organisasi tercapai. Dengan motivasi kerja yang tinggi, karyawan akan bekerja lebih giat didalam melaksanakan pekerjaannya. Sebaliknya dengan motivasi kerja yang rendah karyawan tidak mempunyai semangat bekerja, mudah menyerah, dan kesulitan dalam menyelesaikan pekerjaannya. Karyawan kurang memiliki informasi yang jelas apakah pekerjaan mereka memiliki dampak positif terhadap para penerima manfaatnya yaitu individu atau kelompok yang dilayani organisasi (Blau \& Scott, 1962; Katz \& Kahn, 1966). Signifikansi tugas seringkali tidak pasti di organisasi - organisasi karena beberapa alasan. Pertama, Karyawan di 
organisasi sering menemui prasangka buruk, yang bisa menghalangi mereka untuk merasa bahwa mereka telah mencapai tujuan - tujuan (Scott \& Pandey, 2005) dan membuat mereka ragu apakah misi mereka adalah mungkin (Weick, 1984). Kedua, para karyawan seringkali hanya menerima umpan balik langsung yang sedikit tentang bagaimana tindakan - tindakan mereka mempengaruhi penerima manfaat, yang mungkin membuat mereka ragu apakah misi mereka tercapai atau tidak.

Untuk menciptakan kinerja yang tinggi, dibutuhkan adanya peningkatan kerja yang optimal dan mampu mendayagunakan potensi sumber daya manusia yang dimiliki oleh karyawan guna menciptakan tujuan organisasi, sehingga akan memberikan kontribusi positif bagi perkembangan organisasi. Selain itu, organisasi perlu memperhatikan berbagai faktor yang dapat mempengaruhi motivasi karyawan, dalam hal ini diperlukan adanya peran organisasi dalam meningkatkan motivasi dan menciptakan lingkungan kerja yang kondusif guna mendorong terciptanya sikap dan tindakan yang profesional dalam menyelesaikan pekerjaan sesuai dengan bidang dan tanggung jawab masing - masing. Sumber daya manusia berperan dalam mengolah dan memanfaatkan sumber daya dan material sehingga menjadi produk. Oleh karena itu untuk meningkatkan kinerja, perlu diperhatikan agar sumber daya manusia dapat bekerja secara efisien dan menampilkan kinerja yang bisa memberi sumbangan terhadap produktivitas merupakan masalah mendasar dari berbagai konsep manajemen dan kepemimpinan. Kinerja mengacu pada prestasi kerja karyawan diukur berdasarkan standard atau kriteria yang telah ditetapkan organisasi. Pengelolaan untuk mencapai kinerja karyawan yang sangat tinggi terutama untuk meningkatkan kinerja organisasi secara keseluruhan.

Tujuan dari penelitian ini yaitu untuk mengetahui faktor-faktor motivasi eksternal dan internal yang dapat mempengaruhi kinerja karyawan di PT. XYZ dan untuk mengetahui motivasi manakah (eksternal dan internal) yang paling dominan berpengaruh terhadap peningkatan kinerja karyawan di PT. XYZ yaitu;

1. Untuk mengetahui pengaruh lingkungan kerja fisik terhadap kinerja karyawan pada PT. XYZ.

2. Untuk mengetahui pengaruh balas jasa terhadap kinerja karyawan pada PT. XYZ.

3. Untuk mengetahui pengaruh status terhadap kinerja karyawan pada PT. XYZ.

4. Untuk mengetahui pengaruh lingkungan kerja sosial terhadap kinerja karyawan pada PT. XYZ.

5. Untuk mengetahui pengaruh pengakuan terhadap kinerja karyawan pada PT. XYZ.

6. Untuk mengetahui pengaruh pengawasan terhadap kinerja karyawan pada PT. XYZ.

7. Untuk mengetahui pengaruh pekerjaan itu sendiri terhadap kinerja karyawan pada PT. XYZ.

8. Untuk mengetahui pengaruh prestasi terhadap kinerja karyawan pada PT. XYZ.

Berdasarkan pada latar belakang pemikiran di atas, peneliti tertarik untuk menguji: "Pengaruh Motivasi Karyawan Terhadap Kinerja Karyawan di PT. XYZ".

\section{Tinjauan Pustaka}

Menurut Hasibuan (dalam Sutrisno, 2014:110), motivasi mempersoalkan bagaimana cara mendorong gairah kerja bawahan, agar mereka mau bekerja keras dengan memberikan semua kemampuan dan keterampilan untuk mewujudkan tujuan perusahaan.

Menurut Sedarmayanti (2011: 22), lingkungan kerja fisik adalah semua yang terdapat disekitar tempat kerja yang dapat mempengaruhi pegawai baik secara langsung maupun tidak langsung.

Balas jasa yang berupa kenaikan gaji yang dilakukan berdasarkan masa kerja dan golongan karyawan, pendistribusian gaji yang transparan serta tunjangan kesehatan atau hari 
raya sangat berpengaruh terhadap peningkatan produktivitas kerja karyawan (Sedarmayanti, 2011).

Faktor status (tetap/tidak tetap) menurut Mathis (2012) berpengaruh terhadap peningkatan produktivitas kerja karena dapat memberikan kebanggaan tersendiri terhadap pekerjaannya sehingga peraturan perusahaan, hak dan kewajiban bisa berjalan dengan baik. Menurut Soekanto (Abdulsyani, 2014: 92), status merupakan tempat seseorang secara umum dalam masyarakatnya yang berhubungan dengan orang-orang lain, hubungan dengan orang lain dalam lingkungan pergaulannya, prestisenya dan hak-hak serta kewajibannya.

Menurut Sedarmayanti (2011: 31) menyatakan bahwa lingkungan kerja sosial adalah semua keadaan yang terjadi yang berkaitan dengan hubungan kerja, baik dengan atasan maupun dengan sesama rekan kerja ataupun hubungan dengan bawahan. Lingkungan kerja sosial ini merupakan lingkungan kerja yang tidak bisa diabaikan.

Pengakuan artinya memberikan penghargaan, pujian dan pengakuan yang tepat serta wajar kepada bawahan atas prestasi kerja yang dicapai (Hasibuan, 2012: 221).

Robbin (2011) menyatakan pengawasan itu merupakan suatu proses aktivitas yang sangat mendasar, sehingga membutuhkan seorang manajer untuk menjalankan tugas dan pekerjaan organisasi.

Faktor pekerjaan itu sendiri, sangat berpengaruh terhadap peningkatan produktivitas kerja karyawan dengan melakukan pekerjaan yang sesuai kemampuan yang dimiliki serta merasa senang dengan pekerjaan yang dilakukan saat ini akan memberikan hasil sesuai dengan target perusahaan. Pekerjaan itu sendiri, yaitu isi pekerjaan yang dilakukan oleh seseorang, apak memiliki elemen yang memuaskan (Marihot Tua Efendi, 2012: 290).

Menurut Simamora (2014) prestasi merupakan salah satu bentuk penghargaan kepada karyawan atas prestasi kerja yang telah dilakukan bagi kepentingan perusaahan.

Kerangka pemikiran dalam penelitian ini adalah untuk menguji pengaruh motivasi karyawan terhadap kinerja karyawan di PT. XYZ.

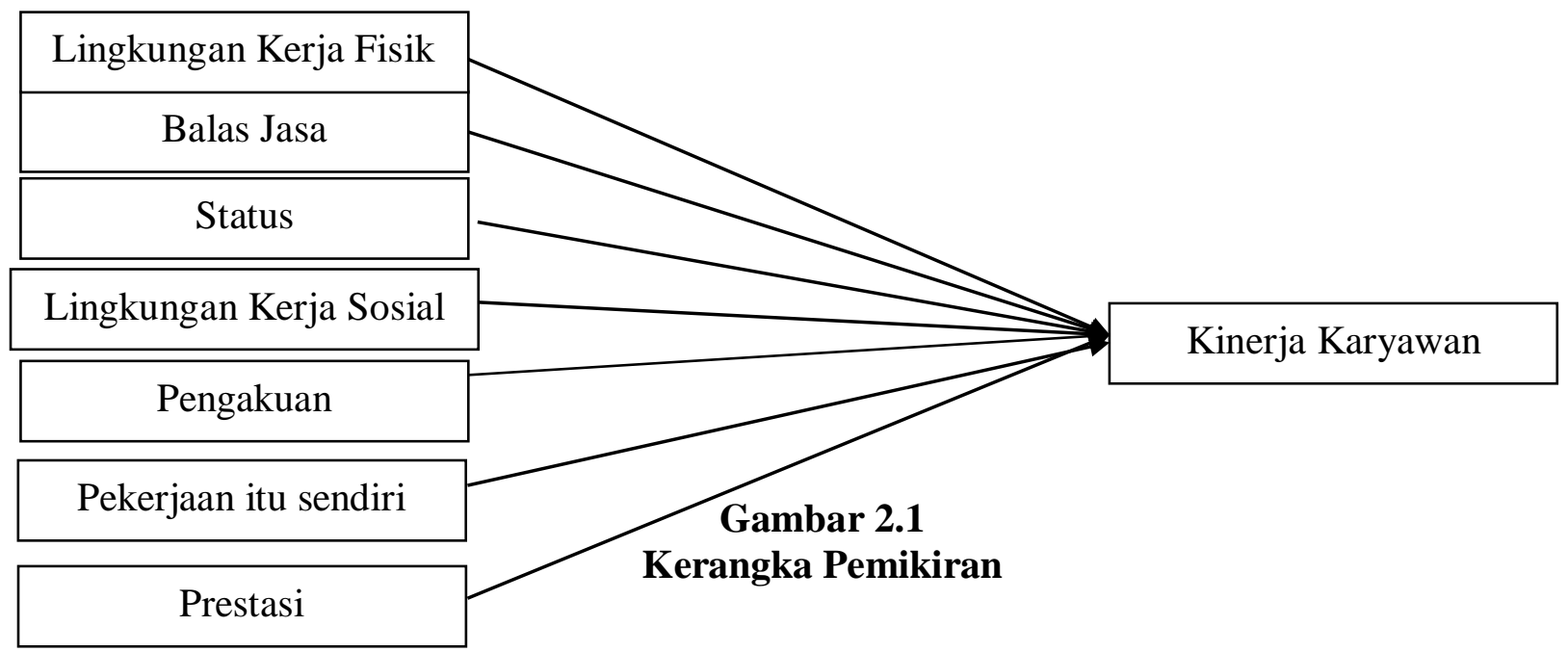

Berdasarkan kerangka pemikiran diatas maka diperoleh hipotesis sebagai berikut:

H1 : Terdapat pengaruh lingkungan kerja fisik terhadap kinerja karyawan

H2 : Terdapat pengaruh balas jasa terhadap kinerja karyawan

H3 : Terdapat pengaruh status terhadap kinerja karyawan

H4 : Terdapat pengaruh lingkungan kerja sosial terhadap kinerja karyawan

H5 : Terdapat pengaruh pengakuan terhadap kinerja karyawan

H6: Terdapat pengaruh pengawasan terhadap kinerja karyawan

H7 :Terdapat pengaruh pekerjaan itu sendiri terhadap kinerja karyawan

H8: Terdapat pengaruh prestasi terhadap kinerja karyawan 


\section{Metodologi}

Metode penelitian yang digunakan dalam penelitian ini metode kuantitatif. Menurut Sugiyono (2012:11) menyatakan metode kuantitatif dapat diartikan sebagai metode penelitian yang berlandaskan pada filsafat positivism, digunakan untuk meneliti pada populasi atau sampel tertentu, pengumpulan data menggunakan instrument penelitian, analisis data bersifat kuantitatif/ statistik, dengan tujuan untuk menguji hipotesis yang telah ditetapkan. Dilihat dari jenisnya, penelitian ini termasuk dalam penelitian survei dimana dalam pemecahan masalahnya adalah dengan cara mengungkapkan hubungan sebab akibat (kausal) antara variabel bebas (lingkungan kerja fisik, balas jasa, status, pelaksanaan dan administrasi, lingkungan kerja sosial, pengakuan, pengawasan, pekerjaan itu sendiri, tanggung jawab, dan prestasi) dan variable terikat (kinerja karyawan). Data yang akan diambil berdasarkan data primer melalui kuesioner.

Populasi adalah wilayah generalisasi yang terdiri atas: obyek/subyek yang mempunyai kualitas dan karakteristik tertentu yang ditetapkan peneliti untuk dipelajari kemudian ditarik kesimpulannya (Sugiyono, 2012:61). Populasi dapat juga disebut sebagai sekumpulan unsur atau elemen yang menjadi objek penelitian, atau himpunan semua yang ingin diketahui. Populasi dalam penelitian ini adalah karyawan PT. XYZ. Sampel adalah bagian dari jumlah dan karakteristik yang dimiliki oleh populasi. Bila populasi besar dan peneliti tidak mempelajari semua yang ada pada populasi (keterbatasan dana, tenaga dan waktu) maka peneliti dapat menggunakan sampel yang diambil dari populasi itu (Sugiyono, 2012:61). Teknik pengambilan sampel dalam penelitian ini menggunakan metode probability sampling. yaitu teknik pengambilan sampel yang memberikan pelunag/kesempatan sama bagi setiap unsur atau anggota populasi untuk dipilih menjadi sampel. Sementara itu, penentuan sampel menggunakan teknik simple random sampling yaitu teknik penentuan sampel dari populasi yang dilakukan secara acak tanpa memperhatikan strata pada populasi itu (Sugiyono, 2012:93). Penentuan jumlah sampel dalam penelitian ini menggunakan rumus Slovin sebagai berikut:

Dimana : $\mathrm{n} \quad$ : Besar Sampel

$$
\mathrm{n}=\frac{\mathrm{N}}{1+\mathrm{N}(\mathrm{e})^{2}}
$$

$\mathrm{N}$ : Besar Populasi

e : Batas kesalahan yang diinginkan/desired margin of error, dalam penarikan sampel dan populasi disini digunakan tingkat kegagalan $5 \%$ yang berarti level of confidence / tingkat keyakinan $95 \%$

Analisis data yang digunakan pada penulisan ini adalah menggunakan analisis statistik yaitu dengan analisis regresi linear berganda dengan bantuan program SPSS versi 21.00. Namun, sebelum melakukan analisis regresi berganda, terlebih dahulu dilakukan pengujian statistik deskriptif, dan asumsiklasik: uji normalitas, uji multikolinearitas, dan uji heteroskedastisitas.

Penelitian ini dilakukan terhadap seluruh karyawan PT. XYZ yang mencakup 127 orang. Gambaran responden pada penelitian ini diuraikan berdasarkan jenis kelamin, usia, pendidikan, dan besarnya pengeluaran perbulan. Tabel 4.1 menunjukkan bahwa dari 127 responden, sebanyak 85 orang (67\%) adalah pria dan 42 orang (33\%) adalah wanita. Hal ini menggambarkan bahwa karyawan PT. XYZ sebagian besar adalah pria.

Tabel 4.1

Profil Responden Berdasarkan Jenis Kelamin

\begin{tabular}{c|c|c|}
\hline Jenis Kelamin & Frekuensi & Persen \\
\hline Pria & 85 & $67 \%$ \\
\hline
\end{tabular}




\begin{tabular}{|l|l|l|}
\hline Wanita & 42 & $33 \%$ \\
\hline
\end{tabular}

Responden dalam penelitian ini juga dikelompokkan menjadi 4 kelompok yaitu kelompok 1 untuk usia 20-25 tahun, kelompok 2 untuk usia 26-30 tahun, kelompok 3 untuk usia 31-40 tahun, dan kelompok 4 untuk lebih dari 40 tahun. Berdasarkan Tabel 4.2 dapat dilihat bahwa responden dalam penelitian ini yang termasuk kelompok usia 1 berjumlah 30 orang (24\%), kelompok 2 berjumlah 34 orang (27\%), kelompok 3 berjumlah 45 orang (35\%), dan kelompok 4 berjumlah 18 orang (14\%).

Tabel 4.2

Profil Responden Berdasarkan Usia

\begin{tabular}{|c|c|c|}
\hline Kelompok Usia & Frekuensi & Persen \\
\hline Kelompok 1 (20-25 tahun) & 30 & $24 \%$ \\
\hline Kelompok 2 (26-30 tahun) & 34 & $27 \%$ \\
\hline Kelompok 3 (31-40 tahun) & 45 & $35 \%$ \\
\hline Kelompok 4 ( $>40$ tahun) & 18 & $14 \%$ \\
\hline
\end{tabular}

Berdasarkan jenjang pendidikan yang telah ditempuhnya, responden dalam penelitian ini dibagi menjadi 5 kelompok yaitu SMP, SMA/SLTA/SMK/SMF, Diploma/D3, Sarjana/ S1, dan S2. Sebagian besar responden memiliki pendidikan hingga S1 yaitu sebanyak 93 orang $(73,2 \%)$, diikuti dengan D3 yaitu sebanyak 20 orang $(15,7 \%)$, diikuti dengan S2 yaitu sebanyak 9 orang (7\%), diikuti dengan SMA/SLTA/SMK/SMF yaitu sebanyak 3 orang $(2,4 \%)$ dan SMP sebanyak 2 orang $(1,6 \%)$.

Tabel 4.3

Profil Responden Berdasarkan Pendidikan

\begin{tabular}{|c|c|c|}
\hline Pendidikan & Frekuensi & Persen \\
\hline SMP & 2 & $1,6 \%$ \\
\hline SMA/SLTA/SMK/SMF & 3 & $2,4 \%$ \\
\hline Diploma/D3 & 20 & $15,7 \%$ \\
\hline Sarjana/ S1 & 93 & $73,2 \%$ \\
\hline S2 & 9 & $7 \%$ \\
\hline
\end{tabular}

Tabel 4.4 menunjukkan bahwa sebanyak 5 responden (4\%) telah bekerja $<6$ bulan, 4 responden (3\%) telah bekerja 6 bulan - 1 tahun, 73 responden (57\%) telah bekerja 1-3 tahun, dan 45 responden $(36 \%)$ telah bekerja $>3$ tahun.

Tabel 4.4

Profil Responden Berdasarkan Lama Bekerja

\begin{tabular}{|c|c|c|}
\hline Lama Bekerja & Frekuensi & Persen \\
\hline$<6$ bulan & 5 & $4 \%$ \\
\hline 6 bulan -1 tahun & 4 & $3 \%$ \\
\hline $1-3$ tahun & 73 & $57 \%$ \\
\hline$>3$ tahun & 45 & $36 \%$ \\
\hline
\end{tabular}

\section{Hasil dan Pembahasan}

Berdasarkan hasil analisis regresi berganda dengan SPSS ini diperoleh rumus persamaan regresi sebagai berikut: 


$$
\begin{aligned}
\mathrm{Y}= & -22,562+0,422 \mathrm{X} 1+0,177 \mathrm{X} 2+0,473 \mathrm{X} 3+0,160 \mathrm{X} 4+0,521 \mathrm{X} 5+0,333 \mathrm{X} 6+ \\
& 0,169 \mathrm{X} 7+0,255 \mathrm{X} 8+\mathrm{e}
\end{aligned}
$$

Dari persamaan diatas dapat diketahui bahwa konstanta sebesar -22,562 menunjukkan setiap kenaikan satu satuan variabel lingkungan kerja fisik $\left(\mathrm{X}_{1}\right)$, balas jasa $\left(\mathrm{X}_{2}\right)$, status $\left(\mathrm{X}_{3}\right)$, lingkungan kerja sosial $\left(\mathrm{X}_{4}\right)$, pengakuan $\left(\mathrm{X}_{5}\right)$, pengawasan $\left(\mathrm{X}_{6}\right)$, pekerjaan itu sendiri $\left(\mathrm{X}_{7}\right)$, dan prestasi $\left(\mathrm{X}_{8}\right)$ akan menyebabkan penurunan Kinerja Karyawan $(\mathrm{Y})$ sebesar 22,562 satuan. Jika variabel lingkungan kerja fisik $\left(\mathrm{X}_{1}\right)$, balas jasa $\left(\mathrm{X}_{2}\right)$, status $\left(\mathrm{X}_{3}\right)$, lingkungan kerja sosial $\left(\mathrm{X}_{4}\right)$, pengakuan $\left(\mathrm{X}_{5}\right)$, pengawasan $\left(\mathrm{X}_{6}\right)$, pekerjaan itu sendiri $\left(\mathrm{X}_{7}\right)$, dan prestasi $\left(\mathrm{X}_{8}\right)$ adalah nol maka kinerja karyawan $(\mathrm{Y})$ adalah -22,562.

Koefisien regresi lingkungan kerja fisik $\left(\mathrm{X}_{1}\right)$ sebesar 0,422 menunjukkan bahwa lingkungan kerja fisik $\left(\mathrm{X}_{1}\right)$ mempunyai hubungan positif dengan kinerja karyawan $(\mathrm{Y})$. Hal ini berarti bila variabel lain (balas jasa $\left(\mathrm{X}_{2}\right)$, status $\left(\mathrm{X}_{3}\right)$, lingkungan kerja sosial $\left(\mathrm{X}_{4}\right)$, pengakuan $\left(\mathrm{X}_{5}\right)$, pengawasan $\left(\mathrm{X}_{6}\right)$, pekerjaan itu sendiri $\left(\mathrm{X}_{7}\right)$, dan prestasi $\left(\mathrm{X}_{8}\right)$ ) konstan maka peningkatan satu satuan lingkungan kerja fisik $\left(\mathrm{X}_{1}\right)$ akan meningkatkan kinerja karyawan (Y) sebesar 0,422 dan sebaliknya.

Koefisien regresi balas jasa $\left(\mathrm{X}_{2}\right)$ sebesar 0,177 menunjukkan bahwa balas jasa $\left(\mathrm{X}_{2}\right)$ mempunyai hubungan positif dengan kinerja karyawan $(\mathrm{Y})$. Hal ini berarti bila variabel lain (lingkungan kerja fisik $\left(\mathrm{X}_{1}\right)$, status $\left(\mathrm{X}_{3}\right)$, lingkungan kerja sosial $\left(\mathrm{X}_{4}\right)$, pengakuan $\left(\mathrm{X}_{5}\right)$, pengawasan $\left(\mathrm{X}_{6}\right)$, pekerjaan itu sendiri $\left(\mathrm{X}_{7}\right)$, dan prestasi $\left(\mathrm{X}_{8}\right)$ ) konstan maka peningkatan satu satuan balas jasa $\left(\mathrm{X}_{2}\right)$ akan meningkatkan kinerja karyawan $(\mathrm{Y})$ sebesar 0,177 dan sebaliknya.

Koefisien regresi status $\left(\mathrm{X}_{3}\right)$ sebesar 0,473 menunjukkan bahwa status $\left(\mathrm{X}_{3}\right)$ mempunyai hubungan positif dengan kinerja karyawan (Y). Hal ini berarti bila variabel lain (lingkungan kerja fisik $\left(\mathrm{X}_{1}\right)$, balas jasa $\left(\mathrm{X}_{2}\right)$, lingkungan kerja sosial $\left(\mathrm{X}_{4}\right)$, pengakuan $\left(\mathrm{X}_{5}\right)$, pengawasan $\left(\mathrm{X}_{6}\right)$, pekerjaan itu sendiri $\left(\mathrm{X}_{7}\right)$, dan prestasi $\left(\mathrm{X}_{8}\right)$ ) konstan maka peningkatan satu satuan status $\left(\mathrm{X}_{3}\right)$ akan meningkatkan kinerja karyawan $(\mathrm{Y})$ sebesar 0,473 dan sebaliknya.

Koefisien regresi lingkungan kerja sosial $\left(\mathrm{X}_{4}\right)$ sebesar 0,160 menunjukkan bahwa lingkungan kerja sosial $\left(\mathrm{X}_{4}\right)$ mempunyai hubungan positif dengan kinerja karyawan (Y). Hal ini berarti bila variabel lain (lingkungan kerja fisik $\left(\mathrm{X}_{1}\right)$, balas jasa $\left(\mathrm{X}_{2}\right)$, status $\left(\mathrm{X}_{3}\right)$, , pengakuan $\left(\mathrm{X}_{5}\right)$, pengawasan $\left(\mathrm{X}_{6}\right)$, pekerjaan itu sendiri $\left(\mathrm{X}_{7}\right)$, dan prestasi $\left(\mathrm{X}_{8}\right)$ ) konstan maka peningkatan satu satuan lingkungan kerja sosial $\left(\mathrm{X}_{4}\right)$ akan meningkatkan kinerja karyawan (Y) sebesar 0,160 dan sebaliknya.

Koefisien regresi pengakuan $\left(\mathrm{X}_{5}\right)$ sebesar 0,521 menunjukkan bahwa pengakuan $\left(\mathrm{X}_{5}\right)$ mempunyai hubungan positif dengan kinerja karyawan $(\mathrm{Y})$. Hal ini berarti bila variabel lain (lingkungan kerja fisik $\left(\mathrm{X}_{1}\right)$, balas jasa $\left(\mathrm{X}_{2}\right)$, status $\left(\mathrm{X}_{3}\right)$, lingkungan kerja sosial $\left(\mathrm{X}_{4}\right)$, pengawasan $\left(\mathrm{X}_{6}\right)$, pekerjaan itu sendiri $\left(\mathrm{X}_{7}\right)$, dan prestasi $\left(\mathrm{X}_{8}\right)$ ) konstan maka peningkatan satu satuan pengakuan $\left(\mathrm{X}_{5}\right)$ akan meningkatkan kinerja karyawan $(\mathrm{Y})$ sebesar 0,521 dan sebaliknya.

Koefisien regresi pengawasan $\left(\mathrm{X}_{6}\right)$ sebesar 0,333 menunjukkan bahwa pengawasan $\left(\mathrm{X}_{6}\right)$ mempunyai hubungan positif dengan kinerja karyawan (Y). Hal ini berarti bila variabel lain (lingkungan kerja fisik $\left(\mathrm{X}_{1}\right)$, balas jasa $\left(\mathrm{X}_{2}\right)$, status $\left(\mathrm{X}_{3}\right)$, lingkungan kerja sosial $\left(\mathrm{X}_{4}\right)$, pengakuan $\left(\mathrm{X}_{5}\right)$, pekerjaan itu sendiri $\left(\mathrm{X}_{7}\right)$, dan prestasi $\left(\mathrm{X}_{8}\right)$ ) konstan maka peningkatan satu satuan pengawasan $\left(\mathrm{X}_{6}\right)$ akan meningkatkan kinerja karyawan $(\mathrm{Y})$ sebesar 0,333 dan sebaliknya.

Koefisien regresi pekerjaan itu sendiri $\left(\mathrm{X}_{7}\right)$ sebesar 0,169 menunjukkan bahwa pekerjaan itu sendiri $\left(\mathrm{X}_{7}\right)$ mempunyai hubungan positif dengan kinerja karyawan (Y). Hal ini berarti bila variabel lain (lingkungan kerja fisik $\left(\mathrm{X}_{1}\right)$, balas jasa $\left(\mathrm{X}_{2}\right)$, status $\left(\mathrm{X}_{3}\right)$, lingkungan kerja sosial $\left(\mathrm{X}_{4}\right)$, pengakuan $\left(\mathrm{X}_{5}\right)$, pengawasan $\left(\mathrm{X}_{6}\right)$, dan prestasi $\left(\mathrm{X}_{8}\right)$ ) konstan maka peningkatan 
satu satuan pekerjaan itu sendiri $\left(\mathrm{X}_{7}\right)$ akan meningkatkan kinerja karyawan $(\mathrm{Y})$ sebesar 0,169 dan sebaliknya.

Koefisien regresi prestasi $\left(\mathrm{X}_{8}\right)$ sebesar 0,255 menunjukkan bahwa prestasi $\left(\mathrm{X}_{8}\right)$ mempunyai hubungan positif dengan kinerja karyawan (Y). Hal ini berarti bila variabel lain (lingkungan kerja fisik $\left(\mathrm{X}_{1}\right)$, balas jasa $\left(\mathrm{X}_{2}\right)$, status $\left(\mathrm{X}_{3}\right)$, lingkungan kerja sosial $\left(\mathrm{X}_{4}\right)$, pengakuan $\left(\mathrm{X}_{5}\right)$, pengawasan $\left(\mathrm{X}_{6}\right)$, pekerjaan itu sendiri $\left(\mathrm{X}_{7}\right)$ ) konstan maka peningkatan satu satuan prestasi $\left(\mathrm{X}_{8}\right)$ akan meningkatkan kinerja karyawan $(\mathrm{Y})$ sebesar 0,255 dan sebaliknya.

Hasil pengolahan data SPSS mengintepretasikan bahwa lingkungan kerja fisik berpengaruh secara signifikan terhadap kinerja karyawan. Hal ini ditunjukkan pada hasil uji t, dimana nilai signifikansi variabel $\mathrm{X}_{1}$ adalah 0,000 dan lebih kecil dari 0,05. Hal ini selaras dengan penelitian Masood Asim (2013), Muhammad Nadeem, Naveed Ahmad, Muhammad Abdullah, dan Naqvi Hamad (2014), Masud Ibrahim dan Veronica Adu Brobbey (2015), Amjad Ali, Li Zhong Bin, Huang Jian Piang dan Zulfiqar Ali (2016), Ukaejiofo Rex Uzonna (2013) yang menyatakan bahwa lingkungan kerja fisik berpengaruh secara signifikan terhadap kinerja karyawan.

Hasil pengolahan data SPSS mengintepretasikan bahwa balas jasa berpengaruh secara signifikan terhadap kinerja karyawan. Hal ini ditunjukkan pada hasil uji t, dimana nilai signifikansi variabel $\mathrm{X}_{2}$ adalah 0,010 dan lebih kecil dari 0,05. Hal ini selaras dengan penelitian Masood Asim (2013), Muhammad Nadeem, Naveed Ahmad, Muhammad Abdullah, dan Naqvi Hamad (2014), Masud Ibrahim dan Veronica Adu Brobbey (2015), Amjad Ali, Li Zhong Bin, Huang Jian Piang dan Zulfiqar Ali (2016), Ukaejiofo Rex Uzonna (2013) yang menyatakan bahwa balas jasa berpengaruh secara signifikan terhadap kinerja karyawan.

Hasil pengolahan data SPSS mengintepretasikan bahwa status berpengaruh secara signifikan terhadap kinerja karyawan. Hal ini ditunjukkan pada hasil uji t, dimana nilai signifikansi variabel $\mathrm{X}_{3}$ adalah 0,012 dan lebih kecil dari 0,05. Hal ini selaras dengan penelitian Masood Asim (2013), Muhammad Nadeem, Naveed Ahmad, Muhammad Abdullah, dan Naqvi Hamad (2014), Masud Ibrahim dan Veronica Adu Brobbey (2015), Amjad Ali, Li Zhong Bin, Huang Jian Piang dan Zulfiqar Ali (2016), Ukaejiofo Rex Uzonna (2013) yang menyatakan bahwa status berpengaruh secara signifikan terhadap kinerja karyawan.

Hasil pengolahan data SPSS mengintepretasikan bahwa lingkungan kerja sosial berpengaruh secara signifikan terhadap kinerja karyawan. Hal ini ditunjukkan pada hasil uji t, dimana nilai signifikansi variabel $\mathrm{X}_{4}$ adalah 0,002 dan lebih kecil dari 0,05. Hal ini selaras dengan penelitian Masood Asim (2013), Muhammad Nadeem, Naveed Ahmad, Muhammad Abdullah, dan Naqvi Hamad (2014), Masud Ibrahim dan Veronica Adu Brobbey (2015), Amjad Ali, Li Zhong Bin, Huang Jian Piang dan Zulfiqar Ali (2016), Ukaejiofo Rex Uzonna (2013) yang menyatakan bahwa lingkungan kerja sosial berpengaruh secara signifikan terhadap kinerja karyawan

Hasil pengolahan data SPSS mengintepretasikan bahwa pengakuan berpengaruh secara signifikan terhadap kinerja karyawan. Hal ini ditunjukkan pada hasil uji t, dimana nilai signifikansi variabel $\mathrm{X}_{5}$ adalah 0,047 dan lebih kecil dari 0,05. Hal ini selaras dengan penelitian Masood Asim (2013), Muhammad Nadeem, Naveed Ahmad, Muhammad Abdullah, dan Naqvi Hamad (2014), Masud Ibrahim dan Veronica Adu Brobbey (2015), Amjad Ali, Li Zhong Bin, Huang Jian Piang dan Zulfiqar Ali (2016), Ukaejiofo Rex Uzonna (2013) yang menyatakan bahwa pengakuan berpengaruh secara signifikan terhadap kinerja karyawan.

Hasil pengolahan data SPSS mengintepretasikan bahwa pengawasan berpengaruh secara signifikan terhadap kinerja karyawan. Hal ini ditunjukkan pada hasil uji t, dimana nilai 
signifikansi variabel $\mathrm{X}_{6}$ adalah 0,001 dan lebih kecil dari 0,05 . Hal ini selaras dengan penelitian Masood Asim (2013), Muhammad Nadeem, Naveed Ahmad, Muhammad Abdullah, dan Naqvi Hamad (2014), Masud Ibrahim dan Veronica Adu Brobbey (2015), Amjad Ali, Li Zhong Bin, Huang Jian Piang dan Zulfiqar Ali (2016), Ukaejiofo Rex Uzonna (2013) yang menyatakan bahwa pengawasan berpengaruh secara signifikan terhadap kinerja karyawan.

Hasil pengolahan data SPSS mengintepretasikan bahwa pekerjaan itu sendiri berpengaruh secara signifikan terhadap kinerja karyawan. Hal ini ditunjukkan pada hasil uji t, dimana nilai signifikansi variabel $\mathrm{X}_{7}$ adalah 0,021 dan lebih kecil dari 0,05. Hal ini selaras dengan penelitian Masood Asim (2013), Muhammad Nadeem, Naveed Ahmad, Muhammad Abdullah, dan Naqvi Hamad (2014), Masud Ibrahim dan Veronica Adu Brobbey (2015), Amjad Ali, Li Zhong Bin, Huang Jian Piang dan Zulfiqar Ali (2016), Ukaejiofo Rex Uzonna (2013) yang menyatakan bahwa pekerjaan itu sendiri berpengaruh secara signifikan terhadap kinerja karyawan.

Hasil pengolahan data SPSS mengintepretasikan bahwa prestasi berpengaruh secara signifikan terhadap kinerja karyawan. Hal ini ditunjukkan pada hasil uji t, dimana nilai signifikansi variabel $\mathrm{X}_{8}$ adalah 0,001 dan lebih kecil dari 0,05. Hal ini selaras dengan penelitian Masood Asim (2013), Muhammad Nadeem, Naveed Ahmad, Muhammad Abdullah, dan Naqvi Hamad (2014), Masud Ibrahim dan Veronica Adu Brobbey (2015), Amjad Ali, Li Zhong Bin, Huang Jian Piang dan Zulfiqar Ali (2016), Ukaejiofo Rex Uzonna (2013) yang menyatakan bahwa prestasi berpengaruh secara signifikan terhadap kinerja karyawan.

Hasil uji ini dapat dilihat pada tabel dibawah ini:

Coefficients $^{\text {a }}$

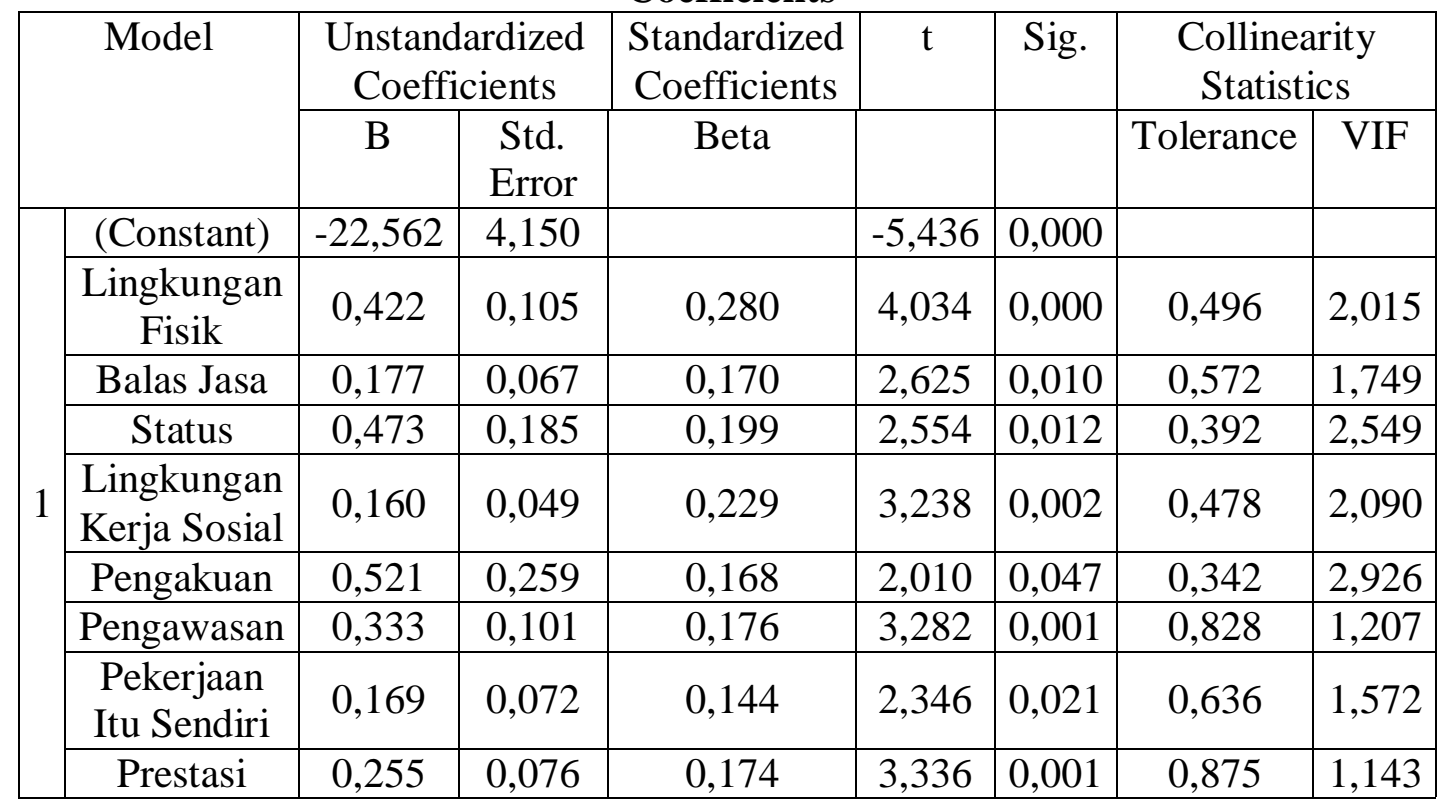

a. Dependent Variable: Kinerja Karyawan

Nilai $\mathrm{R}^{2}$ dalam penelitian ini adalah sebesar 0,718 yang berarti koefisien determinasinya adalah $71,8 \%$. Hal ini menunjukkan bahwa dalam penelitian ini, pengaruh dari variabel lingkungan kerja fisik $\left(\mathrm{X}_{1}\right)$, balas jasa $\left(\mathrm{X}_{2}\right)$, status $\left(\mathrm{X}_{3}\right)$, lingkungan kerja sosial $\left(\mathrm{X}_{4}\right)$, pengakuan $\left(\mathrm{X}_{5}\right)$, pengawasan $\left(\mathrm{X}_{6}\right)$, pekerjaan itu sendiri $\left(\mathrm{X}_{7}\right)$, dan prestasi $\left(\mathrm{X}_{8}\right)$ terhadap variabel Kinerja Karyawan (Y) adalah sebesar 71,8\% sedangkan sisanya 28,2\% dipengaruhi oleh variabel lainnya yang tidak diteliti dalam penelitian ini. 


\section{Kesimpulan}

Berdasarkan hasil pengujian data dalam penelitian ini, menunjukkan bahwa variabel Kinerja Karyawan $(\mathrm{Y})$ dipengaruhi oleh variabel lingkungan kerja fisik $\left(\mathrm{X}_{1}\right)$, balas jasa $\left(\mathrm{X}_{2}\right)$, status $\left(\mathrm{X}_{3}\right)$, lingkungan kerja sosial $\left(\mathrm{X}_{4}\right)$, pengakuan $\left(\mathrm{X}_{5}\right)$, pengawasan $\left(\mathrm{X}_{6}\right)$, pekerjaan itu sendiri $\left(\mathrm{X}_{7}\right)$, dan prestasi $\left(\mathrm{X}_{8}\right)$.

Hasil penelitian ini menunjukkan bahwa masih terdapat 28,2\% faktor lainnya yang berkontribusi pengaruh kepada kinerja karyawan PT. XYZ. Tujuannya adalah agar dapat diketahui faktor independen lain apa yang lebih menyebabkan kinerja karyawan pada PT. XYZ. Selain itu, penulis juga akan memberikan saran-saran bagi penelitian yang akan datang. Adapun saran akdemis tersebut adalah melakukan penelitian terhadap variabel lain di luar motivasi kerja yang berpengaruh terhadap kinerja karyawan PT. XYZ.

\section{Saran}

Hasil penelitian ini menunjukkan bahwa masih terdapat $28,2 \%$ faktor lainnya yang berkontribusi pengaruh kepada kinerja karyawan PT. XYZ. Tujuannya adalah agar dapat diketahui faktor independen lain apa yang lebih menyebabkan kinerja karyawan pada PT. XYZ.

Selain itu, penulis juga akan memberikan saran-saran bagi penelitian yang akan datang. Adapun saran akademis tersebut adalah sebagai berikut:

1. Melakukan penelitian terhadap variabel lain di luar motivasi kerja yang berpengaruh terhadap kinerja karyawan PT. XYZ.

2. Melakukan evaluasi terhadap kebijakan-kebijakan yang berkaitan dengan kinerja karyawan PT. XYZ. Adapun kebijakan yang dapat ditinjau adalah seperti kemampuan kerja, hubungan kerja, kepuasan kerja.

3. Mempertimbangkan adanya suatu program yang dapat memotivasi kinerja karyawan seperti memberikan apresiasi terhadap hal terbaik yang telah dilakukannya untuk perusahaan. Contohnya adalah program "Employee of The Semester" untuk setiap departemen bagi para karyawan yang berprestasi dalam pekerjaan.

4. Memperbanyak pelatihan keterampilan dan seminar bagi para karyawan yang dapat menjadi motivasi mereka untuk bekerja sekaligus menjadi kesadaran bagi mereka bahwa bekerja bukan hanya sekedar untuk mendapatkan uang saja tetapi juga merupakan suatu bentuk tanggung jawab karyawan terhadap perusahaan. Dengan adanya pelatihan keterampilan ini akan memberikan kesempatan bagi para karyawan untuk berkembang dimana perkembangan diri ini juga merupakan salah satu contoh dari peningkatan kinerja karyawan.

\section{Daftar Pustaka}

A.A.Anwar Prabu Mangkunegara. 2011. Manajemen Sumber Daya Manusia Perusahaan. PT.Remaja Rosda Karya, Bandung

A.M. Sardiman. 2012. Interaksi dan Motivasi Belajar Mengajar. Jakarta: Rajawali Pers. Abdulsyani. 2014. Sosiologi: Skematika, Teori, dan Terapan. Jakarta: PT. Bumi Aksara.

Ackah, David. 2014. The Impact of Motivation on Employee Performance in the Manufacturing Industry in Ghana. Global Journal of Management Studies and Researches, 1(5) 2014, Pages: 291-310. ISSN 2345-6086. Academic journalscenter.org/index.php/GJMSR/article/.../pdf_3.

Akdere, M. dan R.E. Azevedo. 2010. Agency Theory Implications for Efficient Contracts in Organization Development. Organization Develop ment. Journal 24(2): 43-54

Asim, Masood. 2013. Impact of Motivation on Employee Performance with Effect of Training: Specific to Education Sector of Pakistan. International Journal of 
Scientific and Research Publications, Volume 3. Issue 9, Spetember 2013. ISSN 2250-3153.

Assagaf, S.C.Y. Dotulong, L.O.H. 2015. Pengaruh Disiplin, motivasi dan Semangat Kerja Terhadap Produktivitas Kerja Pegawai Dinas Pendapatan Daerah Kota Manado. Jurnal EMBA Vol.3 (2) Juni, 639-649

Bangun, Wilson. 2012. Manajemen Sumber Daya Manusia, Erlangga, Bandung

Blau and Scott 1962, Kotz dan Kahn 1966. Formal Organization San Fransisco. Journal of Applied Psychology 2009 Vol. 94 No. 4. 927 - 944

George R. Terry. 2013. Principles of Management. Erlangga, Jakarta

Hasibuan, Malayu. 2012. Manajemen Sumber Daya Manusia. Jakarta: PT Bumi Aksara

Heidjrachman, Ranupandojo dan Suad Husnan. 2012. Manajemen Personalia. BPFEYogyakarta, Yogyakarta.

Kuncoro, Mudrajad. 2013. Metode Riset untuk Bisnis dan Ekonomi. Jakarta : Erlangga

Majid, Abdul. 2014. Strategi Pembelajaran. Bandung: PT Remaja Rosdakarya.

Malhotra, Naresh. 2014. Basic Marketing Research. Pearson Education. England

Marihot Tua Efendi, Hariandja. 2012. Manajemen Sumber Daya Manusia : Pengadaan, Pengembangan, Pengkompensasian, dan Peningkatan Produktivitas Pegawai. Jakarta : Grasindo

Mathis, Robert L. 2012. Manajemen Sumber Daya Manusia, Edisi Pertama Salemba Empat, Jakarta

Nawawi, Hadari. 2012. Metode Penelitian Bidang Sosial. Yogyakarta: Gajah Mada University Press.

Nitisemito, Alex. S. 2013. Manajemen Personalia. Edisi Revisi, Penerbit Ghalia Indonesia Prayitno, Elida. 2012. Motivasi dalam Belajar. Jakarta: IKIP Padang

Prawirosentono, Suyadi . 2011. Manajemen Sumber Daya Manusia Kebijakan Kinerja Karyawan. Yogyakarta:BPFE.

Purwanto, M Ngalim. 2014. Psikologi Pendidikan, Jakarta: PT. Remaja Rosdakarya

Robbins, Stephen P. 2011. Organizational behavior. Fourteenth Edition. Pearson education. New Jersey 07458. 77-89*.

Sarwono. 2013. Metode Penelitian Kuantitatif \& Kualitatif. Yogyakarta; Graha Ilmu

Scott. P. G. and Pandey S. K. 2005. Formal Organization San Fransisco. Journal of Applied Psychology 2009 Vol. 94 No. 4. 927 - 944

Sedarmayanti. 2011. Manajemen Sumber Daya Manusia, Reformasi Birokrasi dan Manajemen Pegawai Negri Sipil. Bandung: PT Refika Aditama

Simamora, Henry. 2014. Manajemen Sumber Daya Manusia. Yogyakarta: STIE YKPN.

Soekanto, Soerjono. 2012. Sosiologi Suatu Pengantar. Jakarta: Rajawali Pers

Sondang, Siagian. 2014. Organisasi Kepemimpinan dan Perilaku Administrasi. PT. Gunung Agung ; Jakarta

Sugiyono. 2012. Metode Penelitian Kuantitatif Kualitatif dan $R \& B$. Bandung: Alfabeta. 


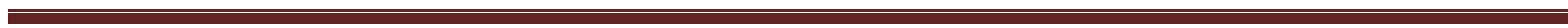
$\cdot$ 